\title{
Human papillomavirus and oropharyngeal cancer, the epidemics, and significance of additional clinical biomarkers for prediction of response to therapy (Review)
}

\author{
TINA DALIANIS \\ Department of Oncology-Pathology, Karolinska Institutet, Cancer Center Karolinska, \\ Karolinska University Hospital, 17176 Stockholm, Sweden
}

Received December 20, 2013; Accepted February 5, 2014

DOI: $10.3892 /$ ijo.2014.2355

\begin{abstract}
In 2007, the International Agency for Research against Cancer (IARC) recognized human papillomavirus (HPV), especially HPV16, besides smoking and alcohol, as a risk factor for oropharyngeal squamous cell carcinoma (OPSCC), where tonsillar and base of tongue cancer dominate. Moreover, during the past decade, in many Western countries, a sharp rise in the incidence of OPSCC, more specifically of HPV-positive OPSCC has been observed. Notably, patients with HPV-positive OPSCC, where the majority are men, particularly never-smokers have a better clinical outcome than patients with HPV-negative OPSCC and other head neck cancer (roughly 80 vs. $40 \%$ disease-free survival with conventional radiotherapy and surgery). This suggests that many patients with HPV-positive OPSCC may not require the more aggressive intensified chemo-radiotherapy given to head neck cancer patients today, and could with somewhat tapered treatment maintain excellent survival, avoiding some of the severe side effects along with intensified treatment. However, before de-intensified treatment is administered additional biomarkers are necessary in combination with HPV-positive status in order to predict and select patients that will respond favorably to therapy. In conclusion, noteworthy issues within this field with an increasing cohort of patients with HPV-positive OPSCC are better-tailored therapy and prevention. Patients with HPV-positive OPSCC, with biomarkers for good response to therapy e.g., low MHC class I, or CD44 expression or high numbers of $\mathrm{CD}^{+}$tumor infiltrating lymphocytes, could be included in randomized trials with less severe therapy. Furthermore, possibilities to
\end{abstract}

Correspondence to: Professor Tina Dalianis, Department of Oncology-Pathology, Karolinska Institutet, Cancer Center Karolinska R8:01, Karolinska University Hospital, 17176 Stockholm, Sweden E-mail: tina.dalianis@ki.se

Key words: tonsillar cancer, base of tongue cancer, oropharyngeal cancer, head and neck cancer, HPV, MHC class I, CD8+ TIL, CD44 screen for HPV-positive OPSCC and to vaccinate boys against HPV infection should be further investigated.

\section{Contents}

1. Introduction

2. Human papillomavirus (HPV)

3. Oropharyngeal squamous cell carcinoma (OPSCC)

4. OPSCC and HPV

5. An HPV induced epidemic of OPSCC

6. HPV and OPSCC and treatment

7. Studies on HPV and other markers in HPV-positive OPSCC in response to treatment

8. Prevention of HPV-positive OPSCC

\section{Introduction}

A correlation between human papillomavirus (HPV), besides smoking and alcohol, in the development of oropharyngeal squamous cell carcinoma (OPSCC) was found and in 2007, this association was recognized by the International Agency for Research against Cancer (IARC)(1-4). Furthermore, in many Western countries a rise in the number of OPSCC cases has been observed, now attributed to an increase of HPV-positive OPSCC cases (5-17). Of note, HPV-positive OPSCC has in general a better clinical outcome than HPV-negative OPSCC and other head neck squamous cell carcinoma (HNSCC) (80 vs. $40 \%$ 5-year disease specific survival with conventional radiotherapy) (1-3,15-19). In parallel, due to this development because of its poor prognosis, HNSCC treatment has become more aggressive with more intensified chemo-radiotherapy administrations, leading to many additional acute and chronic adverse side effects. This intensified therapy may not be necessary for a large majority of patients with HPV-positive OPSCC that earlier did well already with more conventional therapy $(1-3,15,16,20)$. However, not all patients with HPV-positive OPSCC survive, so before tapering therapy it is important to combine positive HPV-status with additional biomarkers in the tumors to identify patients with a very good probability to respond favorably to therapy. Furthermore, it 
would be of benefit to find predictive markers for risk of, or early OPSCC stages, as is done for cervical cancer, as well as introduce HPV-vaccination of boys in order to decrease the effects of the upcoming increase of HPV-positive OPSCC. This review gives an introduction to the field and the important issues of tailored therapy, prediction and prevention. It has special focus on the possibility to select patients with the potential to better respond to therapy and includes some aspects on early prediction of OPSCC, and prevention.

\section{Human papillomavirus (HPV)}

There are over 150 fully sequenced HPV types, with very many isolated from skin, but also a considerable number in mucous tissues $(21,22)$. The cutaneous types can potentially cause skin warts, but their association to skin cancer is unclear, except for epidermodyplasia vercucciformis patients that are sensitive to infections with e.g., HPV5 and 8 resulting in verruca-like papillomatous lesions and multiple skin tumors $(21,22)$. The mucosal types are separated into high-risk (HR) types associated with different cancers, e.g., cervical, vulvar, vaginal penile, anal and OPSCC; and into low-risk (LR) types that are seldom observed in cancer, but often found in benign genital lesions and respiratory papillomas $(21,22)$.

All HPVs are small double stranded circular DNA viruses with genomes of almost $8 \mathrm{~kb}$. The genome arbitrarily divided into a non-coding, an early and a late region is contained within a $52-55 \mathrm{~nm}$ virion encoding for the non-structural 'early proteins' E1-E2, E4-E7, and the two structural viral capsid 'late proteins' L1 and L2 (Fig. 1) (21). E1-E2 and E4-E7 are essential for gene regulation, replication and pathogenesis (21). In HR types the oncogenes E6 and E7, with high affinity to p53 and pRb, respectively, are important for immortalization and transformation (21). More specifically, E6 binds to p53 and causes its degradation, while E7 binds Rb and inhibits its function with deregulation of cell cycle control, also leading to overexpression of the cyclin-dependent kinase inhibitor p16 ${ }^{\text {Ink4a }}$, the latter sometimes used as a surrogate marker for presence of HPV in OPSCC $(16,21,23)$. The L1 major capsid protein contributes to the bulk of the viral capsid (80-90\%) and self-assembles into virus-like particles (VLPs) under certain conditions. VLPs from HPVs and (other viruses) lack viral DNA, and are useful as vaccines and vectors (24-27). Current HPV vaccines consist of VLPs from different HPV types and both contain HPV16 and 18 VLPs $(24,25)$.

\section{Oropharyngeal squamous cell carcinoma (OPSCC)}

OPSCC comprises tonsil and the base of tongue cancer (together accounting for $80 \%$ of the OPSCC cases) as well as cancer of the walls of the pharynx and the soft palate (20). Patients with OPSCC, similar to those with other head neck squamous cell carcinoma (HNSCC) seek medical care when they have symptoms and by then the tumors are relatively large. In earlier studies, clinical outcome for OPSCC, similar to HNSCC at large, was poor with an overall 5-year survival of approximately $25-40 \%$ with conventional radiotherapy and surgery, and it was difficult to predict clinical outcome despite similar stage and histology and treatment $(1-3,20)$. Today, due to the poor prognosis of HNSCC, including that of OPSCC, its curative treatment is more aggressive, with chemo-radiotherapy in addition to surgery when necessary, and in some cases epithelial growth receptor (EGFR) blockers and there has been some improvement of survival $(16,20)$. As always, the aim is to eliminate the malignancy, with as little functional and cosmetic impairment as possible (20). When curative therapy is impossible palliative therapy is administered to lessen discomfort.

\section{OPSCC and HPV}

In 2000, HPV-positive OPSCC, with $>90 \%$ of the cases being HPV16-positive was shown to have a better clinical outcome compared to HPV-negative OPSCC and other HNSCC (80 vs. $40 \%$ 5-year survival) (1-4). Furthermore, HPV-positive and HPV-negative OPSCC were suggested to likely be different entities (1-4,15). Most HPV-positive OPSCC, either with episomal/and or integrated HPV genomes, exhibited E6 and E7 mRNA expression; with p53 expression more often, being normal and with $16^{\text {Ink4a }}$ overexpressed in most cases, in contrast to that observed in HPV-negative OPSCC $(1,18,21,22,28-30)$. In addition, HPV-positive OPSCC was generally less differentiated; more frequently aneuploid compared to HPV-negative OPSCC; and chromosome $3 \mathrm{q}$ often amplified similar to cervical cancer $(31,32)$. Above all, independent of tumor stage, age, gender, differentiation, or DNA ploidy, HPV was a favorable prognostic factor (1-3,31). Moreover, being a never-smoker indicated an even better clinical outcome in patients with HPV-positive OPSCC $(18,33)$. In 2007, the IARC recognized HPV, specially HPV16 as a risk factor for OPSCC (4).

The definition of HPV-positive status in OPSCC is not completely convergent. Mostly, formalin-fixed paraffinembedded (FFPE) tumor biopsies are used to define HPV status and $16^{\text {Ink4a }}$ overexpression assayed by immunohistochemistry (IHC) is used as a surrogate marker by some for HPV (23). In situ hybridization, Southern blots or PCR with general or specific HPV primers for detection of HPV DNA/RNA in addition to primers for cellular genes to assay for DNA amplifiability are also used (34-36). Today many methods including the Hybrid Capture 2; The Roche linear array HPV genotyping test and a PCR bead based multiplex method are available for HPV-typing (37-39). However, most scientists agree that analysis of E6 and E7 mRNA by RT-PCR should be used as a gold standard, since it is more indicative of functional HPV expression (18). Still, it has been reported that the combined presence of HPV DNA tested by PCR and overexpression of p16 by IHC is nearly as specific and sensitive as employing a gold standard (40). Notably, HPV prevalence in OPSCC varies due to methodology used, and due to time-period of analysis, the material, and geographic location (1-3,6,9,12,14-16). In addition, HPV DNA is more often found and of better predictive value in cancer of the tonsil and base of tongue (the tonsil and base of tongue accounting for Waldeyers ring of lymphatic tissue) compared to cancer at other oropharyngeal sites outside the Waldeyers ring (41).

\section{An HPV induced epidemic of OPSCC}

In 2006, a 2.8-fold rise in the incidence of tonsillar cancer was revealed between 1970-2002 in Stockholm, Sweden 


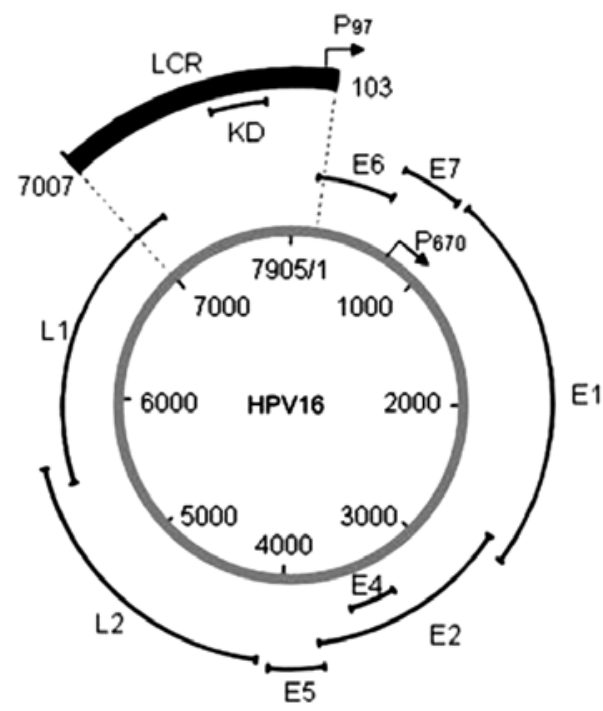

\begin{tabular}{|l|l|}
\hline Viral Protein & Functions and Features \\
\hline E1 & $\begin{array}{l}\text { It forms a heterodimer complex with E2 } \\
\text { and controls viral replication }\end{array}$ \\
\hline E2 & $\begin{array}{l}\text { It regulates early gene promoter and } \\
\text { together with E1 viral DNA replication }\end{array}$ \\
\hline E4 & $\begin{array}{l}\text { It may mediate the viral particle realease } \\
\text { by destabilizing cytokeratin network }\end{array}$ \\
\hline E6 & $\begin{array}{l}\text { It stimulates mitogenic signals of growth } \\
\text { factors }\end{array}$ \\
\hline E7 & $\begin{array}{l}\text { It inactivates many cellular proteins and } \\
\text { is one of the major viral oncoproteins }\end{array}$ \\
\hline L1 & $\begin{array}{l}\text { It inactivates many cellular proteins and } \\
\text { is one of the major viral oncoproteins }\end{array}$ \\
\hline L2 & $\begin{array}{l}\text { It is the major capsid protein and is the } \\
\text { component of the HPV prophylactic } \\
\text { vaccine }\end{array}$ \\
\hline
\end{tabular}

Figure 1. HPV genome and viral proteins, from Tommassino (21) with permission of the publisher.

and in parallel, a 2.9 increase in the percentage $(23-68 \%)$ of HPV-positive tonsillar cancer was found (6). In 2007, an emerging epidemic of HPV associated OPSCC was suggested also in the US (9). This was followed by reports in 2009 and 2010 from Sweden showing a 7-fold increase in HPV-positive tonsillar cancer between 1970-2007 and a decrease of HPV-negative cancer most likely due to less smoking (Fig. 2), and a similar increase in the incidence of HPV-positive base of tongue cancer between 1998-2006 (11,13). In 2011, an analogous development with an increase in incidence of HPV-positive OPSCC and a decline in HPV-negative OPSCC was also reported in the US (17). Furthermore, during much of the same period accumulating reports from many Western countries conveyed both a general increase of OPSCC as well as an increase in the proportion of HPV-positive OPSCC (6-17). The main explanation for this development was attributed to changes in sexual habits with a significant correlation between HPV-positive OPSCC, early sex debut as well as number of oral or vaginal partners (42). Nonetheless, oral- to-oral contact (open-mouth kissing) and oral HPV-transmission at birth could also account for oral HPV infection $(43,44)$. To conclude, in many Western countries there is a presently ongoing epidemic of HPV-associated OPSCC.

\section{HPV and OPSCC and treatment}

New therapeutic and preventive strategies are required since HPV-positive OPSCC today comprises a larger proportion of all HNSCC (16). As stated above, due to its poor prognosis treatment of HNSCC now includes chemo-radiotherapy, surgery and also EGFR inhibitors with more side effects and increasing expenses for society and this is probably not required for $80 \%$ of patients with HPV-positive OPSCC where conventional radiotherapy may be sufficient (16). Nevertheless, to taper therapy, maintaining excellent survival and improved quality of life, as well as decreased costs for society, better approaches to select patients that respond well to therapy are necessary. In some cases, less intensified radiotherapy has

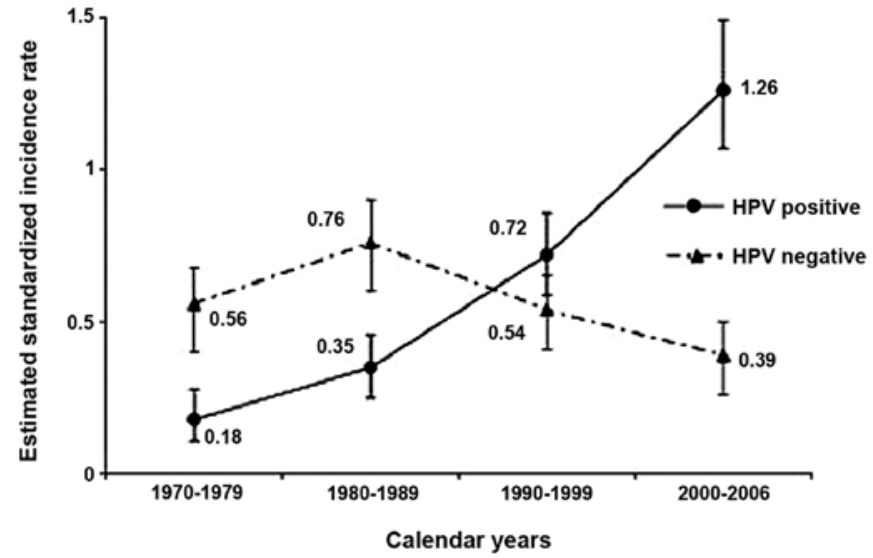

Figure 2. The estimated age standardized incidence rate with $95 \%$ CI of HPV-positive and HPV-negative tonsillar cancer SCC cases per 100,000 person-years in the County of Stockholm, between 1970-2006, from Näsman et al, 2009 (11), with permission from the publisher.

been offered to patients whose tumors have been sensitive to chemotherapy, but the patients have not felt confident to comply to this treatment without having reassurance that this will not affect survival. Therefore it is important to have more objective biomarkers that together with positive HPV status can predict response to therapy.

\section{Studies on HPV and other markers in HPV-positive OPSCC in response to treatment}

Numerous studies have focused on following OPSCC response to treatment based on HPV DNA or RNA status, p16 expression, p53 expression, age gender and smoking as well as the now more recent studies on other biomarkers $(1-3,16,18,33)$. As mentioned above, both the presence of HPV DNA/RNA and p16 overexpression are excellent prognostic markers especially combined together or with being a never smoker $(18,33)$. In fact, with each package year of smoking, the prognosis deteriorates 

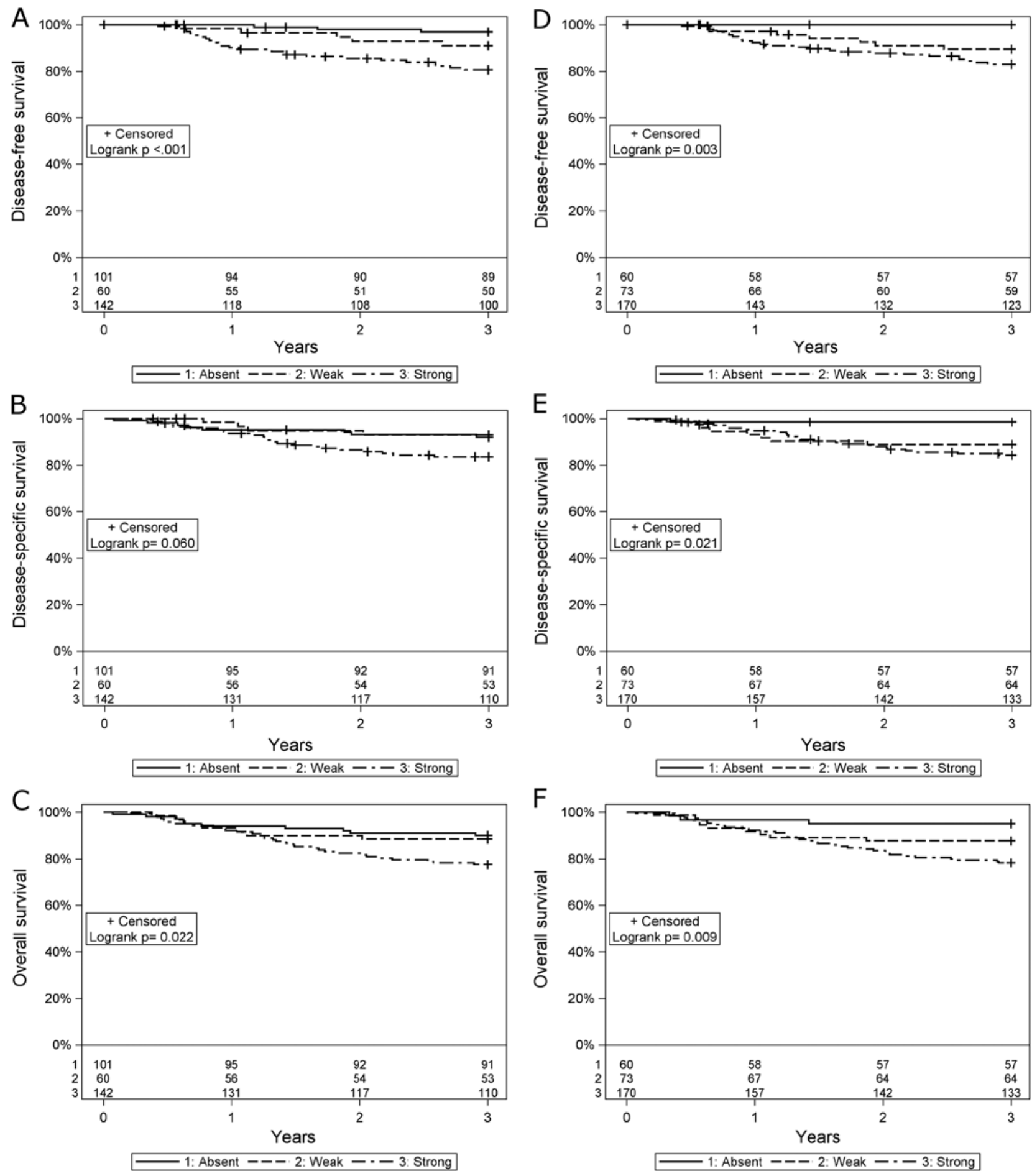

Figure 3. Kaplan-Meier curves for disease-free survival (DFS), disease-specific survival (DSS) and overall survival (OS) in patients with HPV-positive oropharyngeal squamous cell carcinoma (OSCC) with known MHC class I expression, where HCA-2 and HC-10 are two antibodies against HLA class I (the human MHC class I). (A) DFS stratified for HCA-2 intensity; (B) DSS stratified for HCA-2 intensity; (C) OS stratified for HCA-2 intensity; (D) DFS stratified

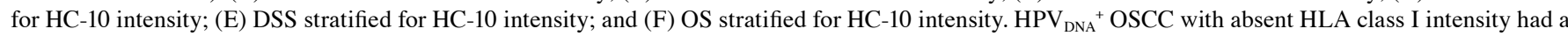
significant better clinical outcome than tumors with strong HLA class I intensity, while weak intensity staining presented an intermediate survival (HCA-2: DFS $p<0.001$; DSS $p=0.060$; OS p $=0.022$; HC-10: DFS $\mathrm{p}=0.003$; DSS $\mathrm{p}=0.021$; and OS $\mathrm{p}=0.009$, with the log-rank test). Notably, the difference observed in the HCA-2 DSS analysis did not reach significance, although the trend was similar. From Näsman et al (46), with permission from the publisher.

(33). However, several markers have also been analyzed in parallel to HPV status and have also shown a very good credibility (45-50). It has been shown that absent/low expression of MHC class I, CD44 or CD98 intensity staining is of very high prognostic value for patients with HPV-positive OPSCC and e.g., for absent MHC class I staining indicates a $95-100 \%$ probability of a 3-year disease-free and overall survival (Fig. 3) (45-49). Furthermore, having high $\mathrm{CD}^{+}$tumor infiltrating lymphocyte (TIL) counts was also of high prognostic value for patients with HPV-positive OPSCC $(50,51)$. MHC class II, Cox-2 expression, or high numbers of $\mathrm{CD} 4^{+} \mathrm{TILs}$ did not influence prognosis for patients with HPV-positive OPSCC $(46,47,51)$. 
The fact that low MHC class I expression in HPV-positive OPSCC was a favorable prognostic factor is to some extent surprising, since downregulation of MHC abrogates the immune response $(45,46)$. Moreover, there was no increase in the number of NK-cells in the tumors (46). However, the low MHC class I expression could be due to high functional HPV activity since both E5 and E7 contribute to downregulation of MHC class I expression and that treatment to some extent increases MHC class I expression enhancing the immune response against these tumors $(45,46)$. Of note, in this respect in experimental models, HPV-positive tumors were curable after cisplatin or radiation therapy only in immunocompetent and not in immunoincompetent mice thus suggesting that a functional immune response was necessary for final elimination of the tumors (52). It is noteworthy that for HPV-negative OPSCC high MHC class I expression was a favorable prognostic factor as was low CD44 intensity expression and high number of CD8 ${ }^{+}$TILs $(45,46,48)$. The data suggest that some prognostic markers could be specific for only HPV-positive OPSCC, or HPV-negative OPSCC, while others could be of more general use.

To obtain more molecular and immunological knowledge would be valuable. In addition, so far none of the markers above select all patients with HPV-positive OPSCC with a favorable clinical outcome. It is therefore important to identify additional biomarkers that can increase our probability to select as many patients as possible for randomized clinical trials with lesser therapy.

Some studies have focused on the role of miRNAs in HPV-associated cancers and have found that the miRNA profiles in HPV-positive OPSCC are more similar to those in HPV-positive cervical cancer as compared to those obtained in HPV-negative OPSCC (53). However, so far no miRNAs have been linked to clinical outcome.

In summary, some information is available with regard to markers e.g., overexpression of $16^{\text {Ink4a }}$, low MHC class I, CD44 and CD98 expression, having high $\mathrm{CD}^{+}$TIL counts, and being a never-smoker to guide treatment strategy for patients with HPV-positive OPSCC $(18,33,45-51)$. In addition, prospective randomized studies including patients with HPV-positive OPSCC and the above markers, using different therapies could be of benefit for the patients and to progress towards bettertailored treatment. Nevertheless, there is still an urgent need to identify additional markers, since the ones above do not identify all the patients with a high probability of a good response to therapy.

\section{Prevention of HPV-positive OPSCC}

HPV16 is detected in $80-90 \%$ of all HPV-positive OPSCC indicating that the present HPV vaccines should be able to eventually counteract the ongoing epidemic increase of HPV-positive OPSCC, but this could take time (1-4). Oral HPV prevalence has been stated to be approximately $3-9 \%$, and transmitted by oral-genital or oral-oral contact, or by maternal transmission $(43,54-58)$. Nonetheless, due to the vast production of saliva, oral HPV prevalence is relatively problematic to screen compared to cervical HPV prevalence and may therefore yield false negative results more often. However, based on unpublished data we suggest that a very high oral HPV signal may indicate the presence of an HPV-positive OPSCC. Serology has also been attempted to predict HPV-associated disease (59). Other studies have focused on cytology, but so far this has not been very useful (60). Should screening for HPV-positive OPSCC become necessary, most likely high HPV signals in mouthwashes could still be the best type of approach.

Finally, since HPV-positive OPSCC is still increasing in many Western countries, and the HPV vaccine has the potential to prevent also oral HPV infection (61), it would be of importance to vaccinate both girls and boys.

\section{Acknowledgements}

This study was supported in part by the Swedish Research Council, the Swedish Cancer Foundation, the Stockholm Cancer Society, the Stockholm City Council and the Karolinska Institutet, Sweden.

\section{References}

1. Gillison ML, Koch WM, Capone RB, Spafford M, Westra WH, Wu L, Zahurak ML, Daniel RW, Viglione M, Symer DE, Shah KV and Sidransky D: Evidence for a causal association between human papillomavirus and a subset of head and neck cancers. J Natl Cancer Inst 92: 709-720, 2000.

2. Mellin H, Friesland S, Lewensohn R, Dalianis $T$ and Munck-Wikland E: Human papillomavirus (HPV) DNA in tonsillar cancer: clinical correlates, risk of relapse, and survival. Int J Cancer 89: 300-304, 2000.

3. Dahlstrand HM and Dalianis T: Presence and influence of human papillomaviruses (HPV) in tonsillar cancer. Adv Cancer Res 93: 59-89, 2005.

4. WHO: IARC Monographs on the Evaluation of Carcinogenic Risk to Humans. International Agency for Research on Cancer, Lyon, 2007.

5. Robinson KL and Macfarlane GJ: Oropharyngeal cancer incidence and mortality in Scotland: are rates still increasing? Oral Oncol 39: 31-36, 2003.

6. Hammarstedt L, Lindquist D, Dahlstrand H, Romanitan M, Dahlgren LO, Joneberg J, Creson N, Lindholm J, Ye W, Dalianis T and Munck-Wikland E: Human papillomavirus as a risk factor for the increase in incidence of tonsillar cancer. Int $\mathrm{J}$ Cancer 119: 2620-2623, 2006.

7. Conway DI, Stockton DL, Warnakulasuriya KA, Ogden G and Macpherson LM: Incidence of oral and oropharyngeal cancer in United Kingdom (1990-1999) - recent trends and regional variation. Oral Oncol 42: 586-592, 2006.

8. Hammarstedt L, Dahlstrand H, Lindquist D, Onelöv L, Ryott M, Luo J, Dalianis T, Ye W and Munck-Wikland E: The incidence of tonsillar cancer in Sweden is increasing. Acta Otolaryngol 1279: 988-992, 2007.

9. Sturgis EM and Cinciripini PM: Trends in head and neck cancer incidence in relation to smoking prevalence: an emerging epidemic of human papillomavirus-associated cancers? Cancer 110: 1429-1435, 2007.

10. Chaturvedi AK, Engels EA, Anderson WF and Gillison ML: Incidence trends for human papillomavirus-related and -unrelated oral squamous cell carcinomas in the United States. J Clin Oncol 26: 612-619, 2008.

11. Nasman A, Attner P, Hammarstedt L, Du J, Eriksson M, Giraud G, Sparén P, Ye W, Dahlstrand H, Munck-Wikland E and Dalianis T: Incidence of human papillomavirus (HPV) positive tonsillar carcinoma in Stockholm, Sweden: an epidemic of viralinduced carcinoma? Int J Cancer 125: 362-366, 2009.

12. Braakhuis BJ, Visser O and Leemans CR: Oral and oropharyngeal cancer in The Netherlands between 1989 and 2006: increasing incidence, but not in young adults. Oral Oncol 45: e85-e89, 2009.

13. Attner P, Du J, Nasman A, Hammarstedt L, Ramqvist T, Lindholm J, Marklund L, Dalianis T and Munck-Wikland E: The role of human papillomavirus in the increased incidence of base of tongue cancer. Int J Cancer 126: 2879-2884, 2010. 
14. Marur S, D'Souza G, Westra WH and Forastiere AA: HPV-associated head and neck cancer: a virus-related cancer epidemic. Lancet Oncol 11: 781-789, 2010.

15. Ramqvist $T$ and Dalianis T: Oropharyngeal epidemic and human papillomavirus. Emerg Infect Dis 16: 1671-1677, 2010.

16. Ramqvist $\mathrm{T}$ and Dalianis $\mathrm{T}$ : An epidemic of oropharyngeal squamous cell carcinoma (OSCC) due to human papillomavirus (HPV) infection and aspects of treatment and prevention. Anticancer Res 31: 1515-1519, 2011.

17. Chaturvedi AK, Engels EA, Pfeiffer RM, Hernandez BY, Xiao W, Kim E, Jiang B, Goodman MT, Sibug-Saber M, Cozen W, Liu L, Lynch CF, Wentzensen N, Jordan RC, Altekruse S, Anderson WF, Rosenberg PS and Gillison ML: Human papillomavirus and rising oropharyngeal cancer incidence in the United States. J Clin Oncol 29: 4294-4301, 2011

18. Lindquist D, Romanitan M, Hammarstedt L, Nasman A, Dahlstrand H, Lindholm J, Onelöv L, Ramqvist T, Ye W, Munck-Wikland E and Dalianis T: Human papillomavirus is a favourable prognostic factor in tonsillar cancer and its oncogenic role is supported by the expression of E6 and E7. Mol Oncol 1: 350-355, 2007.

19. Attner P, Du J, Näsman A, Hammarstedt L, Ramqvist $T$, Lindholm J, Marklund L, Dalianis T and Munck-Wikland E: Human papillomavirus and survival in patients with base of tongue cancer. Int J Cancer 128: 2892-2897, 2011.

20. Licitra L, Bernier J, Grandi C, Merlano M, Bruzzi P and Lefebvre JL: Cancer of the oropharynx. Crit Rev Oncol Hematol 41: 107-122, 2002

21. Tommasino M: The human papillomavirus family and carcinogenesis. Semin Cancer Biol: Dec 4, 2013 (Epub ahead of print). pii: S1044-579X(13)00123-5. doi: 10.1016/j. semcancer.2013.11.002.

22. Zur Hausen H: Papillomavirus infections: a major cause of human cancer. In: Infections Causing Human Cancer: Wiley-VCH Verlag, Weinheim, pp145-243, 2006

23. Oguejiofor KK, Hall JS, Mani N, Douglas C, Slevin NJ, Homer J, Hall $G$ and West CM: The prognostic significance of the biomarker p16 in oropharyngeal squamous cell carcinoma. Clin Oncol (R Coll Radiol) 25: 630-638, 2013.

24. Paavonen J, Jenkins D, Bosch FX, Naud P, Salmerón J, Wheeler CM, Chow SN, Apter DL, Kitchener HC, Castellsague X, de Carvalho NS, Skinner SR, Harper DM, Hedrick JA, Jaisamrarn U, Limson GA, Dionne M, Quint W, Spiessens B, Peeters P, Struyf F, Wieting SL, Lehtinen MO and Dubin G: HPV PATRICIA study group: Efficacy of a prophylactic adjuvanted bivalent L1 virus-like-particle vaccine against infection with human papillomavirus types 16 and 18 in young women: an interim analysis of a phase III double-blind, randomised controlled trial. Lancet 369: 2161-2170, 2007.

25. Future II Study Group: Qvadrivalent vaccine against human papillomavirus to prevent high-graded cervical lesions. N Engl J Med 356: 1915-1927, 2007.

26. Ramqvist T, Andreasson $\mathrm{K}$ and Dalianis $\mathrm{T}$ : Vaccination, immune and gene therapy based on virus-like particles against viral infections and cancer. Expert Opin Biol Ther 7: 997-1007, 2007.

27. Dalianis T: Immunotherapy for polyomaviruses: opportunities and challenges. Immunotherapy 4: 617-628, 2012.

28. Mellin H, Dahlgren L, Munck-Wikland E, Lindholm J, Rabbani H, Kalantari M and Dalianis T: Human papillomavirus type 16 is episomal and a high viral load may be correlated to better prognosis in tonsillar cancer. Int J Cancer 102: 152-158, 2002.

29. Koskinen WJ, Chen RW, Leivo I, Mäkitie A, Bäck L, Kontio R, Suuronen R, Lindqvist C, Auvinen E, Molijn A, Quint WG, Vaheri A and Aaltonen LM: Prevalence and physical status of human papillomavirus in squamous cell carcinomas of the head and neck. Int J Cancer 107: 401-406, 2003.

30. Mellin Dahlstrand H, Lindquist D, Bjornestal L, Ohlsson A, Dalianis T, Munck-Wikland E and Elmberger G: P16(INK4a) correlates to human papillomavirus presence, response to radiotherapy and clinical outcome in tonsillar carcinoma. Anticancer Res 25: 4375-4383, 2005.

31. Mellin H, Friesland S, Auer G, Dalianis T and Munck-Wikland E. Human papillomavirus and DNA ploidy in tonsillar cancer correlation to prognosis. Anticancer Res 23: 2821-2828, 2003.

32. Dahlgren L, Mellin H, Wangsa D, Heselmeyer-Haddad K, Björnestål L, Lindholm J, Munck-Wikland E, Auer G, Ried T and Dalianis T: Comparative genomic hybridization analysis of tonsillar cancer reveals a different pattern of genomic imbalances in human papillomavirus-positive and -negative tumors. Int J Cancer 107: 244-249, 2003.
33. Ang KK, Harris J, Wheeler R, Weber R, Rosenthal DI, Nguyen-Tan PF, Westra WH, Chung CH, Jordan RC, Lu C, Kim H, Axelrod R, Silverman CC, Redmond KP and Gillison ML: Human papillomavirus and survival of patients with oropharyngeal cancer. N Engl J Med 363: 24-35, 2010.

34. de Roda Husman AM, Walboomers JM, van den Brule AJ, Meijer CJ and Snijders PJ: The use of general primers GP5 and GP6 elongated at their 3' ends with adjacent highly conserved sequences improves human papillomavirus detection by PCR J Gen Virol 76: 1057-1062, 1995.

35. Tieben LM, ter Schegget J, Minnaar RP, Bouwes Bavinck JN, Berkhout RJ, Vermeer BJ, Jebbink MF and Smits HL: Detection of cutaneous and genital HPV types in clinical samples by PCR using consensus primers. J Virol Methods 42: 265-279, 1993

36. van den Brule AJ, Pol R, Fransen-Daalmeijer N, Schouls LM, Meijer CJ and Snijders PJ: GP5 ${ }^{+} / 6^{+}$PCR followed by reverse line blot analysis enables rapid and high-throughput identification of human papillomavirus genotypes. J Clin Microbiol 40: 779-787, 2002.

37. Clavel C, Masure M, Bory JP, Putaud I, Mangeonjean C, Lorenzato M, Gabriel R and Quereux C: Hybrid Capture II-based human papillomavirus detection, a sensitive test to detect in routine high-grade cervical lesions: a preliminary study on 1518 women. Br J Cancer 80: 1306-1311, 1999.

38. Gravitt PE, Peyton CL, Apple RJ and Wheeler CM: Genotyping of 27 human papillomavirus types by using L1 consensus PCR products by a single-hybridization, reverse line blot detection method. J Clin Microbiol 36: 3020-3027, 1998

39. Schmitt M, Bravo IG, Snijders PJ, Gissmann L, Pawlita M and Waterboer T: Bead-based multiplex genotyping of human papillomaviruses. J Clin Microbiol 44: 504-512, 2006.

40. Smeets SJ, Hesselink AT, Speel EJ, Haesevoets A, Snijders PJ, Pawlita M, Meijer CJ, Braakhuis BJ, Leemans CR and Brakenhoff RH: A novel algorithm for reliable detection of human papillomavirus in paraffin-embedded head and neck cancer specimen. Int J Cancer 121: 2465-2472, 2007.

41. Marklund L, Näsman A, Ramqvist T, Dalianis T, MunckWikland E and Hammarstedt L: Prevalence of human papillomavirus and survival in oropharyngeal cancer other than tonsil or base of tongue cancer. Cancer Med 1: 82-88, 2012.

42. Anaya-Saavedra G, Ramirez-Amador V, Irigoyen-Camacho ME, Garcia-Cuellar CM, Guido-Jimenez M, Mendez-Martinez R and García-Carrancá A: High association of human papillomavirus infection with oral cancer: a case-control study. Arch Med Res 39: 189-197, 2008

43. D'Souza G, Agrawal Y, Halpern J, Bodison S and Gillison ML: Oral sexual behaviors associated with prevalent oral human papillomavirus infection. J Infect Dis 199: 1263-1269, 2009.

44. Syrjänen S and Puranen M: Human papillomavirus infections in children: the potential role of maternal transmission. Crit Rev Oral Biol Med 11: 259-274, 2000.

45. Näsman A, Andersson E, Nordfors C, Grün N, Johansson H, Munck-Wikland E, Massucci G, Dalianis T and Ramqvist T: MHC class I expression in HPV positive and negative tonsillar squamous cell carcinoma in correlation to clinical outcome. Int $\mathrm{J}$ Cancer 132: 72-81, 2013.

46. Näsman A, Andersson E, Marklund L, Tertipis N, HammarstedtNordenwall L, Nyberg T, Munck-Wikland E, Masucci GV, Ramqvist T and Dalianis T: HLA class I and II expression in oropharyngeal squamous cell carcinoma in relation to tumor HPV status and clinical outcome. PloS One 8: e7702543, 2013.

47. Lindquist D, Ahrlund-Richter A, Tarján M, Tot T and Dalianis T: Intense CD44 expression is a negative prognostic factor in tonsillar and base of tongue cancer. Anticancer Res 32: 153-161, 2012.

48. Näsman A, Nordfors C, Grün N, Munck-Wikland E, Ramqvist T, Marklund L, Lindquist D and Dalianis T: Absent/weak CD44 intensity and positive human papillomavirus (HPV) status in oropharyngeal squamous cell carcinoma indicates a very high survival. Cancer Med 2: 507-518, 2013.

49. Rietbergen MM, Martens-de Kemp SR, Bloemena E, Witte BI, Brink A, Baatenburg de Jong RJ, Leemans CR, Braakhuis BJ and Brakenhoff RH: Cancer stem cell enrichment marker CD98: A prognostic factor for survival in patients with human papillomavirus-positive oropharyngeal cancer. Eur J Cancer: Dec 4, 2013 (Epub ahead of print). pii: S0959-8049(13)01005-8. doi: 10.1016/j.ejca.2013.11.010.

50. Näsman A, Romanitan M, Nordfors C, Grün N, Johansson H, Hammarstedt L, Marklund L, Munck-Wikland E, Dalianis T and Ramqvist T: Tumor infiltrating $\mathrm{CD}^{+}$and Foxp $3^{+}$lymphocytes correlate to clinical outcome and human papillomavirus (HPV) status in tonsillar cancer. PLoS One 7: e38711, 2012. 
51. Nordfors C, Grün N, Tertipis N, Ahrlund-Richter A, Haeggblom L, Sivars L, Du J, Nyberg T, Marklund L, Munck-Wikland E, Näsman A, Ramqvist T and Dalianis T: CD8(+) and CD4(+) tumour infiltrating lymphocytes in relation to human papillomavirus status and clinical outcome in tonsillar and base of tongue squamous cell carcinoma. Eur J Cancer 49: 2522-2530, 2013.

52. Spanos WC, Nowicki P, Lee DW, Hoover A, Hostager B, Gupta A, Anderson ME and Lee JH: Immune response during therapy with cisplatin or radiation for human papillomavirusrelated head and neck cancer. Arch Otolaryngol Head Neck Surg 135: 1137-1146, 2009.

53. Lajer CB, Garnæs E, Friis-Hansen L, Norrild B, Therkildsen MH, Glud M, Rossing M, Lajer H, Svane D, Skotte L, Specht L, Buchwald $\mathrm{C}$ and Nielsen FC: The role of miRNAs in human papilloma virus (HPV)-associated cancers: bridging between HPV-related head and neck cancer and cervical cancer. Br J Cancer 106: 1526-1534, 2012.

54. Kreimer AR, Bhatia RK, Messeguer AL, Gonzalez P, Herrero R and Giuliano AR: Oral human papillomavirus in healthy individuals: a systematic review of the literature. Sex Transm Dis 37: 386-391, 2010.

55. Rautava J and Syrjanen S: Human papillomavirus infections in the oral mucosa. J Am Dent Assoc 142: 905-914, 2011.

56. Du J, Nordfors C, Ahrlund-Richter A, Sobkowiak M Romanitan M, Näsman A, Andersson S, Ramqvist T and Dalianis T: Prevalence of oral human papillomavirus infection among youth, Sweden. Emerg Infect Dis 18: 1468-1471, 2012.
57. Nordfors C, Grün N, Haeggblom L, Tertipis N, Sivars L, Mattebo M, Larsson M, Häggström-Nordin E, Tydén T, Ramqvist $\mathrm{T}$ and Dalianis T: Oral human papillomavirus prevalence in high school students of one municipality in Sweden. Scand J Infect Dis 45: 878-881, 2013.

58. Steinau M, Hariri S, Gillison ML, Broutian TR, Dunne EF, Tong ZY, Markowitz LE and Unger ER: Cervical and oral HPV prevalence among females in the United States. J Infect Dis: Jan 10, 2014 (Epub ahead of print).

59. D'Souza G, Kreimer AR, Viscidi R, Pawlita M, Fakhry C, Koch WM, Westra WH and Gillison ML: Case-control study of human papillomavirus and oropharyngeal cancer. N Engl J Med 356: 1944-1956, 2007.

60. Fakhry C, Rosenthal BT, Clark DP and Gillison ML: Associations between oral HPV16 infection and cytopathology: evaluation of an oropharyngeal 'pap-test equivalent' in high-risk populations. Cancer Prev Res 4: 1378-1384, 2011.

61. Herrero R, Quint W, Hildesheim A, Gonzalez P, Struijk L, Katki HA, Porras C, Schiffman M, Rodriguez AC, Solomon D, Jimenez S, Schiller JT, Lowy DR, van Doorn LJ, Wacholder S and Kreimer AR; CVT Vaccine Group: Reduced prevalence of oral human papillomavirus (HPV) 4 years after bivalent HPV vaccination in a randomized clinical trial in Costa Rica. PLoS One 8: e68329, 2013. 